\title{
Phase I Final Report
}

\section{"Conversion of Low Temperature Waste Heat Utilizing Hermetic Organic Rankine Cycle"}

\author{
Barber-Nichols Inc. \\ $6325 \mathrm{~W} .55^{\text {th }}$ Ave \\ Arvada, Co 80002 \\ 303-421-8111
}

Prepared by:

Robert L. Fuller, Principle Investigator

DOE award: \#DE-FG02-04ER83906.

Barber-Nichols Inc. would like to recognize the support of the Department of Energy under award \#DE-FG02-04ER83906.

Any opinions, findings, and conclusions or recommendations expressed in this material are those of the author and do not necessarily reflect the views of the Department of Energy.

Distribution: Unlimited, no proprietary or intellectual property is contained in this report 


\section{TABLE OF CONTENTS}

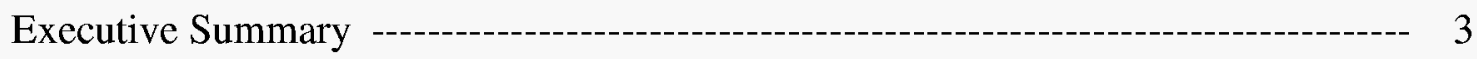

Introduction -----

Fluid Selection -

Figure 1 ---------------------------------------------------------------------------- 6

Design Case Study ----_- 6

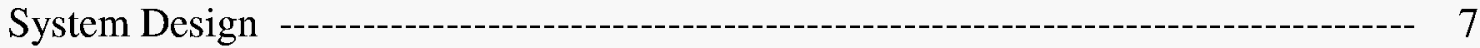

Figure 2 ------------------------------------------------------------------------- 7

50 kWe System Design

Figure 3 --

100 kWe System Design

Figure 5 ---------------------------------------------------------------------------- 11

Figure 6 - -

250 kWe System Design

Figure 7 ------------------------------------------------------------------ 12

Power Conversion and Plant Control ---

Converter Description - -

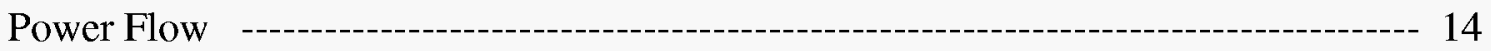

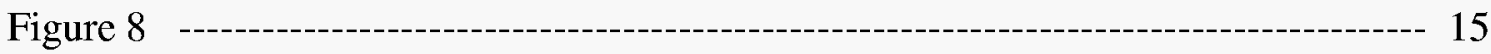

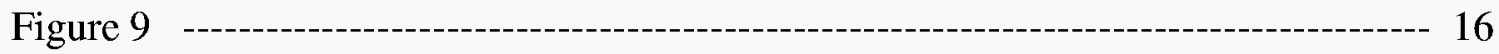

Startup ---o--on 16

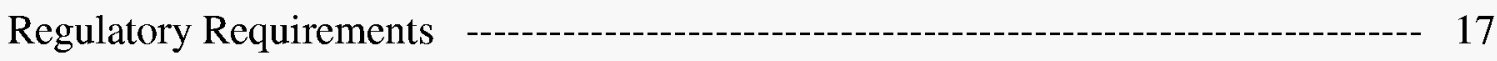

Summary ---

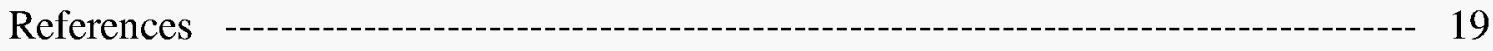




\section{Executive Summary-}

The design of waste heat recovery using the organic Rankine cycle (ORC) engine is updated. Advances in power electronics with lower cost enable the use of a single shaft, high-speed generator eliminating wear items and allowing hermetic sealing of the working fluid. This allows maintenance free operation and a compact configuration that lowers cost, enabling new market opportunities.

\section{Introduction-}

Organic Rankine cycle waste heat recovery power plants are not a new idea. Common uses of this technology are seen in binary geothermal, cement plant, and combustion engine bottoming cycles. The typical configuration of this equipment includes a highspeed turbine, speed reducing gearbox, and an induction or synchronous generator. These power plants have seen limited production due to the high-cost of engineering and construction relative to the plant output power. Typical installations are in areas that have a fixed source of waste heat that has high availability and in an area of high electric costs. A high-speed turbine is often necessary based on the resource temperature, the working fluid physical properties, and the power output level.

Particular customer requirements can affect the ORC design. The selection of the working fluid is often of great customer importance. The end user may be averse to working fluids that have elevated toxicity and flammability ratings (per MSDS Material Safety Data Sheets). This is often due to the location of the plant in a vehicle or populated area. Other requirements may include packaging constraints, environmental concerns, and condensing media (type and temperature). Power plant levels for ORC systems have ranged from a few kilowatts $(\mathrm{kW})$ to many megawatts $(\mathrm{MW})$.

The power level lower range is set by the ability to obtain a reasonable cost per unit power $(\$ / \mathrm{kWe})$. A range of markets was analyzed with regard for a modular, stackable design. For this study, the lower limit was set, with preliminary market research, at 50 $\mathrm{kWe}$. The upper limit of $250 \mathrm{kWe}$ is set by the need for a modular unit, transportable by truck. Systems larger than $250 \mathrm{kWe}$ risk a system volume larger than standard truck transport. With an estimated volume for the power generation equipment and heat exchangers, the maximum estimated power level for a reasonably sized is obtained. This also corresponds well to the turbine wheel sizing that can be obtained in the automotive and truck turbocharger market.

A custom turbine wheel is often a dominant cost in low-medium volume ORC designs. The use of a modified, off-the-shelf turbocharger turbine is envisioned as an excellent method of cost savings. An intermediate power point of $100 \mathrm{kWe}$ was selected for comparison purposes. The three power level analysis allows extrapolation for power levels above or below $50 \mathrm{kWe}$ and $250 \mathrm{kWe}$.

A system level approach was taken to determine the lowest cost per unit of power produced over the size range. This was initially done for systems that would produce 
electric power for distribution to the grid. Due to utility company requirements for regulatory agency equipment approval, the cost of these systems can be higher than if the power is utilized in some other manner such as an "in the fence" process that can disregard traditional voltage and frequency stability and system protection. The final selected design configuration is an example of such process. This is for an over the road diesel truck to improve gas mileage and reduce emissions.

\section{Fluid Selection-}

Fluid selection is one of the most important contributors to overall cycle performance. The fluid thermodynamic and fluid dynamic properties, as well as material compatibility, flammability, and toxicity must be analyzed relative to a customer's needs. As part of the Phase I effort, a survey of applicable fluids was done. A limited list of suitable working fluids was made:

\begin{tabular}{|c|c|c|c|c|}
\hline $\begin{array}{l}\text { ORC } \\
\text { Fluid } \\
\text { Table }\end{array}$ & & & & \\
\hline Fluid & Comments & $\begin{array}{l}\text { Fluid } \\
\text { Stability } \\
\text { Study }\end{array}$ & $\begin{array}{l}100 \text { deg } F \\
\text { Condensing } \\
\text { Pressure }\end{array}$ & Flammable \\
\hline Toluene & Highest Efficiency, Fluid Data Available & yes & 1 psia & yes \\
\hline $\begin{array}{l}\text { HFC- } \\
245 f a\end{array}$ & $\begin{array}{l}\text { High Molecular Weight, Non } \\
\text { Greenhouse }\end{array}$ & Limited & 33 psia & no \\
\hline $\mathrm{R} 134$ & Non Greenhouse, Higher Pressure & no & 138 psia & no \\
\hline $\begin{array}{l}\text { Fluorinal } \\
50\end{array}$ & Trifluoroethanol Water Mix & yes & 2 psia & yes \\
\hline $\begin{array}{l}\text { Fluorinal } \\
85\end{array}$ & $\begin{array}{l}\text { Trifluoroethanol Water Mix, Fluid Data } \\
\text { Available }\end{array}$ & yes & 2 psia & yes \\
\hline IC4 & Geothermal Applications & from use & 52 & yes \\
\hline IC5 & Geothermal Applications & from use & 15 & yes \\
\hline Light Oils & Biomass Plants in Europe & no & 100 & yes \\
\hline
\end{tabular}

Table 1- ORC Fluid Consideration

The fluid selection list could be expanded to include other fluids; however, due to environmental and/or cost issues these fluids have not been included. A large number of Freon based fluids that have historically been utilized are now banned due to greenhouse gas issues.

Several attributes are needed for a suitable ORC fluid. Above atmospheric condensing pressures allow a system to be designed with less rigor relative to sub-atmospheric system. In the sub-atmospheric system, any non-condensable gases that can leak into the system due to reduced pressure, will collect in the condenser and reduce performance substantially. It is easier to add working fluid due to a small leak than have to extract the non-condensable elements from the condenser. 
Flammability and toxicity are often customer related issues. Flammable fluids also require hazardous location wiring, sensors, and valves, adding to the cost. Flammable and toxic materials near a structure are often not allowed due to safety and insurance concerns.

Another consideration for the fluid is the effect on turbine design. The fluid properties, waste heat temperature, flow rate, condensing pressure, and desired power output are all variables that dictate the turbine design. Typically, the customer desires the highest power output possible, improving the financial aspect of investing in ORC equipment. Thus, the highest efficiency turbine design is prescribed. This typically dictates the best operating speed for the turbine. The turbine typically wants to operate at a high speed that is not suitable for direct coupling to a grid synchronous running speed.

Fluid stability is also an important consideration. As the fluid is heated, it has the potential to break down into undesirable forms. Some of these forms can cause system degradation. Other forms can be toxic. Overall fluid stability is a major concern, especially at elevated temperatures. Researching the fluid stability issue identified two studies that had comprehensively studied this issue. One fluid study involved toluene, the other Fluorinal $85(1,2)$. Even though a study directly involving Fluorinal 50 was not discovered, it is not unreasonable to extend the stability research to this fluid. The HFC245 fa (3) fluid addition is due to the good physical properties obtained with the fluorobased fluid that can be used as a substitute for other Freon working fluids that are now banned. The molecular weight of the HFC-245fa fluid results in good turbine performance with reasonable cycle efficiencies. This fluid has not been extensively tested regarding stability, but initial indications when testing this fluid for use in airconditioning compressor seized bearing tests indicate low susceptibility to breakdown.

The paramount consideration for the working fluid is the ability to construct a thermodynamic cycle with high efficiency. Three working fluids were chosen for this study: Toluene, HFC-245fa, and Fluorinal 50. These fluids were chosen from the list in Table 1 based on the market trends seen by Barber-Nichols for compact ORC cycles in the $50 \mathrm{~kW}$ to $250 \mathrm{~kW}$ power range. The theoretical efficiency versus resource temperature (turbine inlet temperature) is shown in figure 1. To simplify the figure and provide an objective measure for the fluid selection case, the list of fluids was limited to three choices. These three choices were further analyzed, where practical, to include a recuperated cycle.

It is clear from this chart that a higher waste heat temperature gives generally greater cycle efficiency. This allows higher electric output per unit of waste heat input. This can also be a measure of unit cost for the equipment per unit of output power, $\$ / \mathrm{kWe}$. From a market standpoint, the best business case can be obtained for the higher waste heat temperature resources. At some reduced waste heat resource temperature, the potential market size will be reduced due to the high cost of the equipment with lower power outputs. 


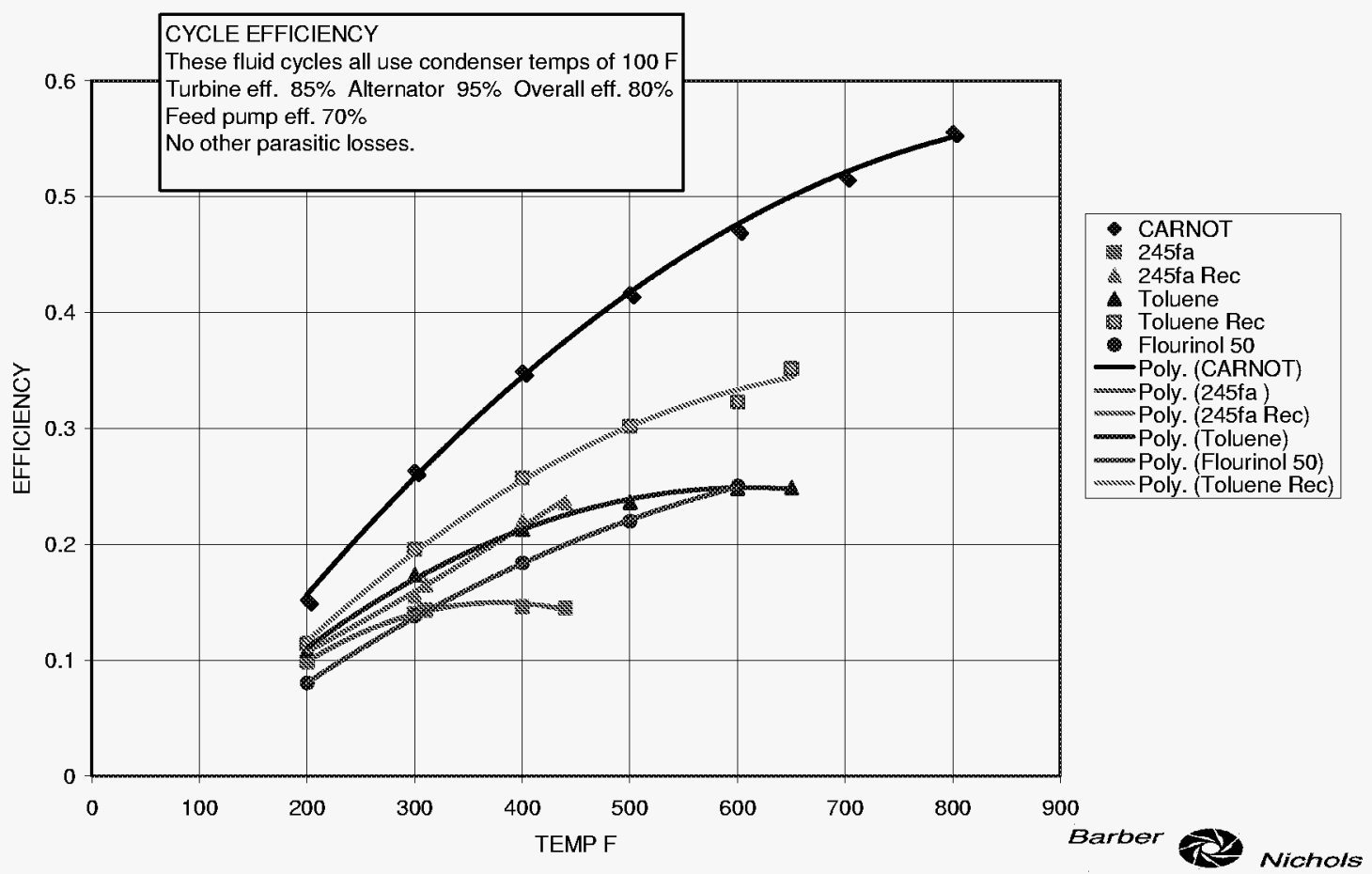

Figure 1- Cycle Efficiency Comparison for 3 Working Fluids

Due to the physical properties of the various fluids, it would be very difficult to have a standard turbine or heat exchanger design that could be utilized for all the working fluids and potential temperatures. A range of heat exchangers and turbine designs could be pieced together for waste heat resource. A large amount of engineering resources would be necessary for this endeavor in anticipation of a marketplace. It is much more reasonable from a business and product development viewpoint to perform a point design for a high volume application and adapt that point design for other applications as they may arise.

\section{Design Case Study-}

Three arbitrary power points were considered for the design case studies. This was done primarily to determine cost and cost breakpoints for the various components for the system. The three considered power points are $50 \mathrm{~kW}, 100 \mathrm{~kW}$, and $250 \mathrm{~kW}$. The goal of the overall design is to be able to stack the systems in a parallel arrangement to provide power for a multiple of the chosen power. This modular arrangement can add to the economies of scale envisioned for volume production. 


\section{System Designs-}

The basic system starting point design is intended for exhaust waste heat from small scale combustion processes. This dictates the use of a working fluid capable of higher temperature operation. Typical combustion waste heat is $500 \mathrm{deg} F$ and above. The exhaust waste heat of a small, recuperated turbine on the market is $540 \mathrm{deg} F$ at full power. This exhaust stream is ideal for a bottoming cycle using an ORC system. From figure 1, the anticipated efficiency at the high-speed generator terminals is over $30 \%$ for a recuperated cycle using Toluene working fluid. The available exhaust temperature from diesel and gasoline engine exhaust approaches $1000 \mathrm{deg} F$. This temperature range indicates efficiencies above $20 \%$ and approaching $30 \%$ are practical. As the temperatures increase, the risk of working fluid breakdown is high. Heat exchanger design becomes important to minimize hot spots that will elevate the working fluid temperature above the recommended values. At very high temperatures, the material cost of the equipment is an important factor to consider. The materials of construction that survive at high temperature are more expensive than low temperature materials.

Establishing a baseline of $600 \mathrm{deg} F$, the cycle analysis can begin. Common ORC cycle components are shown in figure 2 . The heat exchanger array typically consists of a preheater, evaporator, super-heater, recuperator, and condenser.

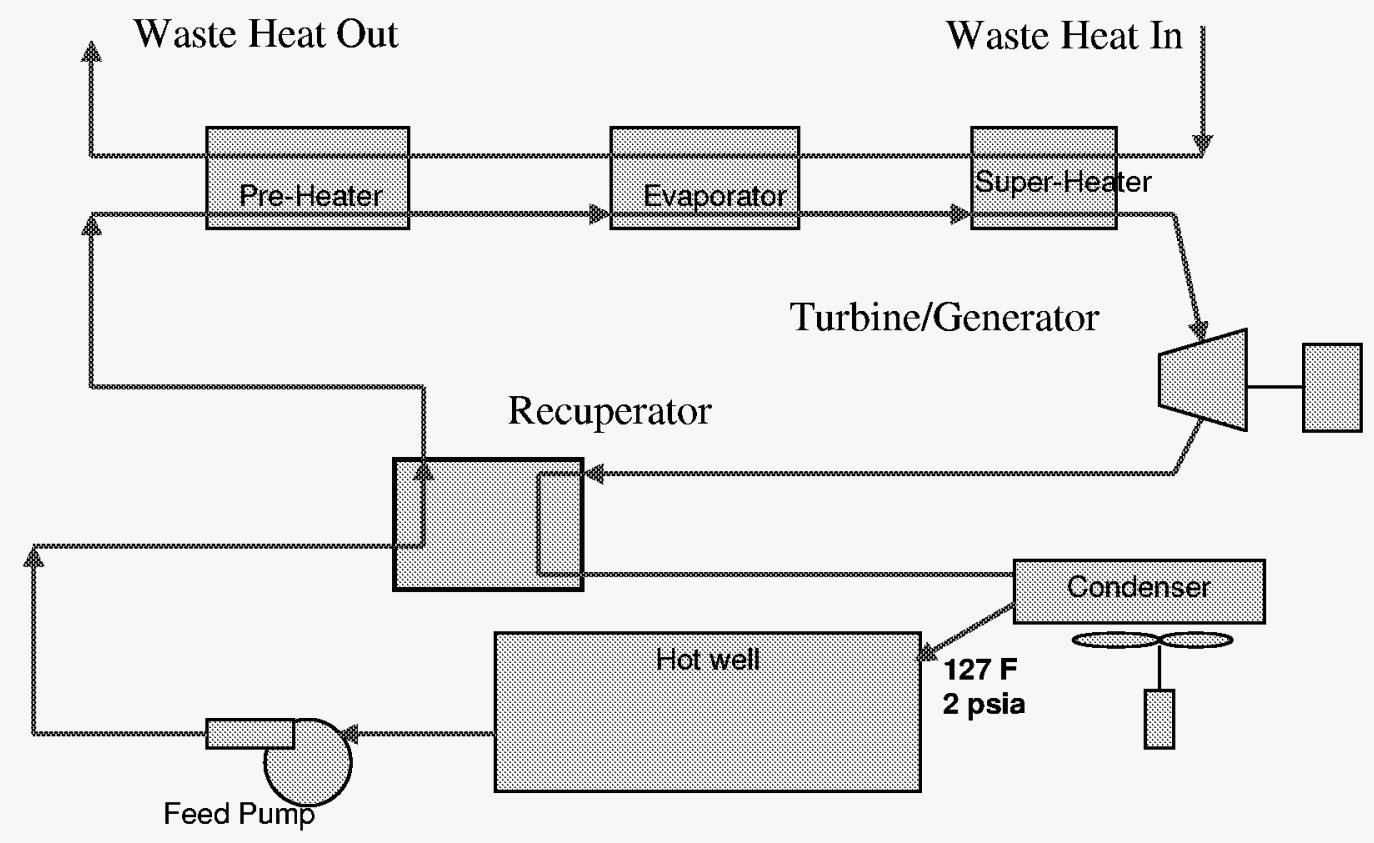

Figure 2- Representative Components of Waste Heat ORC System

The power conditioning equipment is an important part of the high-speed, hermetic turbine/generator design and is treated in a later section. A description of the cycle follows. The working fluid is pumped to the working pressure with the feed pump from the hot well. The fluid is heated by the exhaust gas from the turbine in the recuperator. The fluid is the heated in the pre-heater prior to evaporation and superheating. 
Superheating is shown in this cycle, but may not be cost-effective depending on the working fluid and the economics of purchasing the additional heat exchanger. The working fluid (gas) enters the turbine where it is expanded, creating torque to drive the generator. If the exhaust gas contains significant heat, then it is introduced to the recuperator to preheat the incoming liquid in the cycle. The gas enters the condenser and the liquid is dumped in to the hot well. The hot well is sized for proper inventory management during startup, run, and shutdown. The feed pump is typically located in the hot well, submerged in the working fluid. Some instances allow a small boost pump in the hot well with the feed pump on the opposite end of the high-speed shaft from the turbine.

\section{0 kWe System Design-}

A preliminary proposed design was developed for analyzing the cost for a grid-connected $50 \mathrm{kWe}$ system with defined waste heat source. The $50 \mathrm{kWe}$ size dictated a 208/220/240 $\mathrm{VAC}$ grid connection due to the lower power level. The lowest cost system in terms of $\$ / \mathrm{kW}$ is from a high temperature heat source. The primary heat source is presumed to be exhaust gas from an internal combustion process. Exhaust gas temperatures can approach $1000 \mathrm{deg} \mathrm{F}$ and lead to the high ORC cycle efficiencies necessary for low $\$ / \mathrm{kWe}$ cost. Other potential markets that have high temperature heat sources include cement plants and trough solar installations. These applications have temperatures above 550 degrees F. Designing an ORC system that will have the widest potential market at this power level necessitates the lowest possible anticipated operating temperature.

The cycle design is then chosen for the maximum turbine inlet temperature that can cover a large range of waste heat temperatures. If a $1000 \mathrm{deg} F$ heat source is used, and the turbine inlet temperature is held to a much lower temperature, then the heat exchanger design is much different than for a lower temperature source. The materials and sizing of the 1000 deg $F$ capable heat exchangers is much different than for 550-600 degree $F$ source. Custom heat exchangers may be necessary for each application while keeping the turbine/generator design common. High temperature materials may not be cost effective for a customer who has a more moderate temperature waste heat resource. It is however, important to design the turbine/generator for a lower inlet temperature. To maintain the power level, the mass flow must increase. This is a trade-off that is very complicated and must be done with knowledge of the potential market.

To reduce the cost of the turbo-generator components and have long working fluid life, the turbine inlet temperature was limited to 550 degrees $\mathrm{F}$ and below. Two different cycles were tailored to a diesel engine exhaust waste heat. The diesel engine was chosen because of the consistent output of the waste heat, the availability (hours per day) of the waste heat, and the manufacturing volume potential. An added benefit of this approach is the potential for emissions mitigation.

The cycle points are described in table 2 . Both cycles are without a recuperator for lowest cost per unit of power. 


\begin{tabular}{|l|r|r|}
\hline & $\begin{array}{l}\text { 50 kWe } \\
\text { Cycle }\end{array}$ & \\
\hline & & \\
\hline Fluid & $\begin{array}{l}\text { Fluorinal } \\
50\end{array}$ & Toluene \\
\hline & & \\
\hline Turbine Inlet Temp (deg F) & 475 & 450 \\
\hline Turbine Inlet Pressure (psia) & 450 & 185 \\
\hline Turbine Out Temp (deg F) & 116 & 260 \\
\hline Turbine Out Press (psia) & 3 & 2 \\
\hline Condensing Temperature (deg F) & 115 & 122 \\
\hline Condensing Pressure (psia) & 2.9 & 1.7 \\
\hline Mass Flow (lb/sec) & 0.65 & 0.9 \\
\hline $\begin{array}{l}\text { Cycle Efficiency (\% from } \\
\text { Generator) }\end{array}$ & 21.9 & 23 \\
\hline
\end{tabular}

Table 2: $50 \mathrm{kWe}$ Cycle Data for Two Different Working Fluids

Choosing the Fluorinal 50 cycle, components can be designed and specified for cost estimation. The turbine/generator design concept is shown below in figure 3:

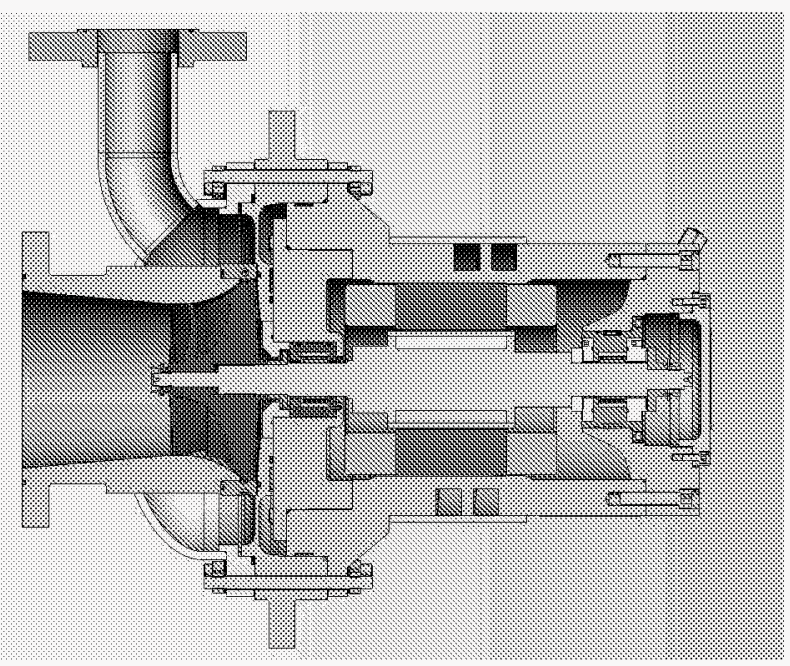

Figure 3: Turbine/Generator Design Concept for $50 \mathrm{kWe}$

This particular design operates at $60 \mathrm{krpm}$, the feed pump sizing at this speed had very small features which precluded adaptation on this shaft. Specifications for the heat exchangers were generated for costing. The power conversion electronics cost was also estimated. The top level system costs are shown in table 3: 


\begin{tabular}{|l|r|}
\hline & 50 kWE Cost Estimate \\
\hline & $1000 /$ yr quantity \\
\hline Turbine Generator & $\$ 12,060.00$ \\
\hline Feed Pump & $\$ 1,200.00$ \\
\hline Hot Well & $\$ 300.00$ \\
\hline Power Conditioning/Control & $\$ 9,500.00$ \\
\hline Heat Exchangers & $\$ 13,500.00$ \\
\hline Piping and Instrumentation & $\$ 2,000.00$ \\
\hline & $\$ 38,560.00$ \\
\hline Total & $\$ 771.20$ \\
\hline T/kW
\end{tabular}

Table 3: System Cost Estimate for $50 \mathrm{kWe}$ Output Level

\section{0 kWe System Design-}

The same design philosophy was used for the $100 \mathrm{kWe}$ design that was used for the 50 $\mathrm{kWe}$ design. The maximum turbine inlet temperature was set below 600 degree $\mathrm{F}$ to allow the broadest possible market for the turbo/generator while recognizing the need for custom heat exchanger designs based on the application.

The $100 \mathrm{kWe}$ case was taken from a similar study done by Barber-Nichols Inc. for a trough solar powered system designed for a private client. In this case the turbine inlet temperature was set at 520 degrees $F$ with a working pressure of 275 psia. The recuperated cycle conditions are as shown in Table 4:

\begin{tabular}{|l|r|}
\hline & 100 kWe Cycle \\
\hline & \\
\hline Fluid & Toluene \\
\hline & 520 \\
\hline Turbine Inlet Temp (deg F) & 275 \\
\hline Turbine Inlet Pressure (psia) & 342 \\
\hline Turbine Out Temp (deg F) & 3.2 \\
\hline Turbine Out Press (psia) & 342 \\
\hline Recuperator Inlet Temp (deg F) & 175 \\
Recuperator Outlet Temp (deg F) & 127 \\
\hline Condensing Temperature (deg F) & 2.5 \\
\hline Condensing Pressure (psia) & 130 \\
\hline Recuperator Liq In Temp (deg F) & 291 \\
Recuperator Liq Out Temp (deg F) & 4.6 \\
\hline Mass Flow (lb/sec) & 23 \\
\hline Cycle Efficiency (\% from Generator) & \\
\hline
\end{tabular}

Table 4: $100 \mathrm{kWe}$ Recuperated Cycle Information

This cycle information can be used to specify the components for cost estimation purposes. The use of parametric solid modeling allows for a reconstruction of the various parts needed for the turbine/generator quoting. Figure 5 and 6 show the $100 \mathrm{kWe}$ turbine generator assembly and system. 


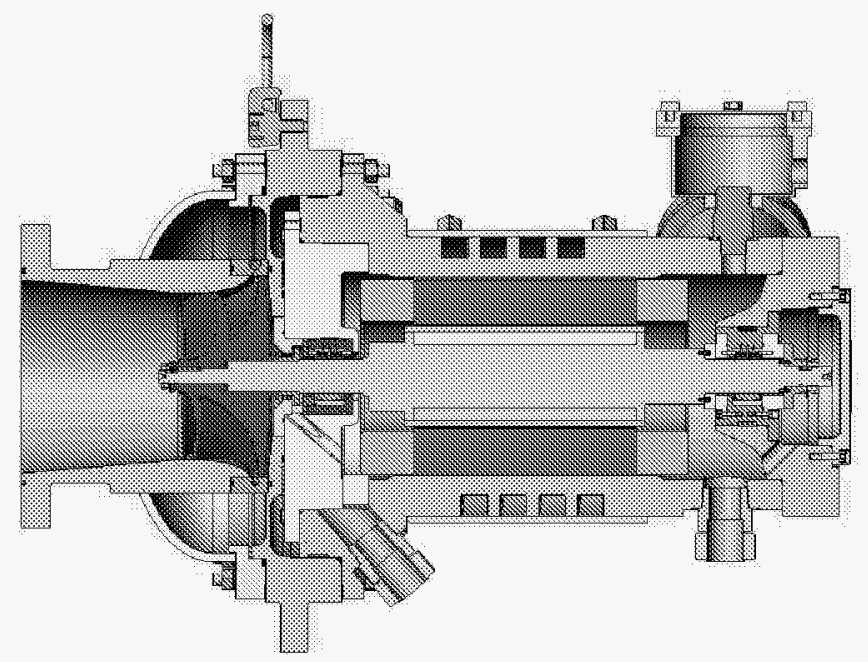

Figure 5: Section View of $100 \mathrm{kWe}$ Turbine Generator

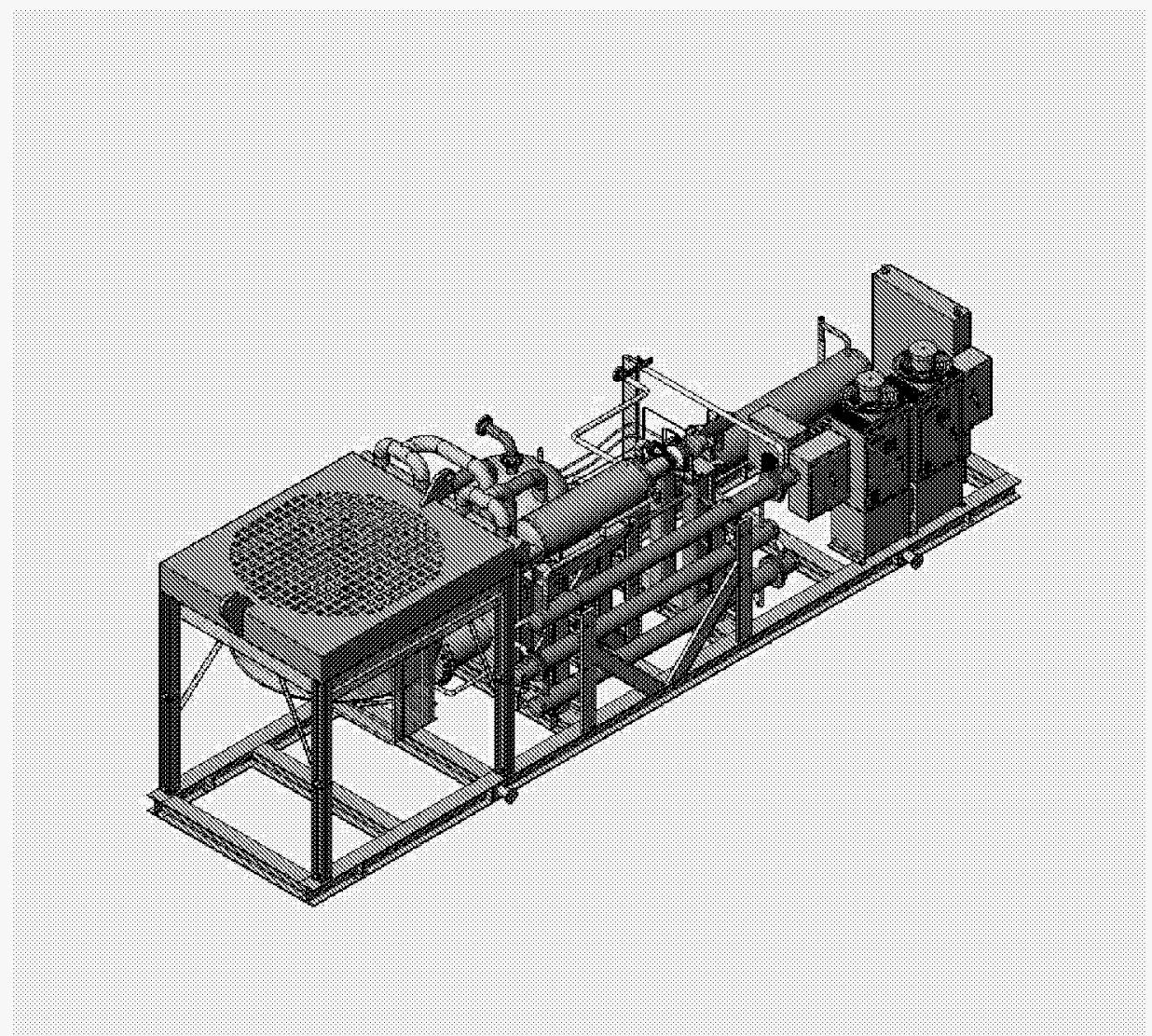

Figure 6: Exterior View of $100 \mathrm{kWe}$ ORC System on Skid 
The various component models enable the estimation of fabrication costs for the turbine generator as well as the other components in the system. The $100 \mathrm{kWe}$ system is design for $480 \mathrm{VAC}$ grid operation. The cost does not include fluid cost, installation, or site engineering costs. Table 4 shows the cost breakdown for the major components for the system:

\begin{tabular}{|l|r|}
\hline & $100 \mathrm{kWE}$ Cost Estimate \\
\hline & $1000 / \mathrm{yr}$ quantity \\
\hline Turbine Generator & $\$ 13,500.00$ \\
\hline Feed Pump & $\$ 1,500.00$ \\
\hline Hot Well & $\$ 550.00$ \\
\hline Power Conditioning/Control & $\$ 13,500.00$ \\
\hline Heat Exchangers & $\$ 16,900.00$ \\
\hline Piping and Instrumentation & $\$ 4,500.00$ \\
\hline & $\$ 49,010.00$ \\
\hline Total & $\$ 490.10$
\end{tabular}

Table 4: $100 \mathrm{kWe}$ System Cost Estimate

\section{0 kWe System Design-}

The $250 \mathrm{kWe}$ system design is an extension of the $100 \mathrm{kWe}$ design. A suitable turbine inlet temperature and working fluid mass flow was defined to enable a design to be performed for cost estimate purposes. The design was scaled from the $100 \mathrm{kWe}$ design and is quite similar. A comparison on turbine wheel size is shown in figure 7.
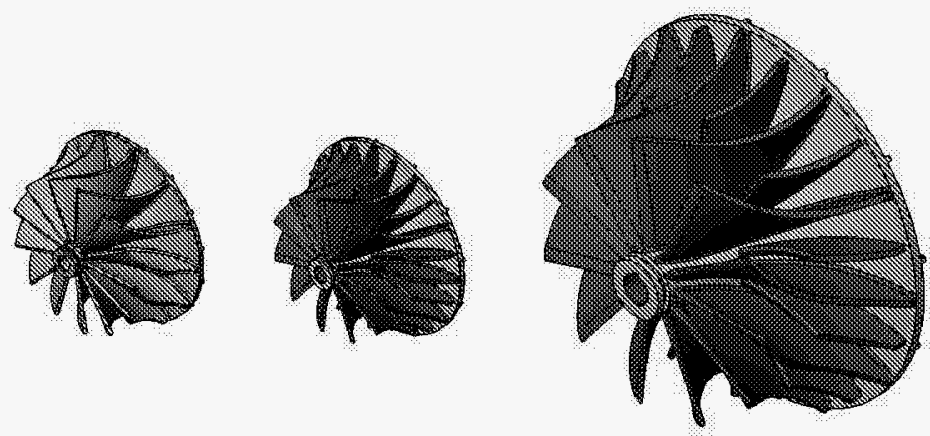

Figure 7: Turbine Wheel Size, $50 \mathrm{~kW}, 100 \mathrm{~kW}$, and $250 \mathrm{~kW}$ Output 
As seen in this figure, the $250 \mathrm{~kW}$ turbine wheel size is quite large (12") compared to the lower power level (5"-6") sizes. Identifying a commercially available turbine wheel for modification purposes was difficult. Due to this the costing of the turbine/generator for this system was higher relative to the output power. Very high volumes at this power level could offset the turbine cost. The power conditioning for grid connection at this power level was lower on a $\$ / \mathrm{kW}$ basis. This was due to the availability of off-the-shelf components at this power level on the marketplace. The cost estimate is shown in table 5 .

\begin{tabular}{|l|r|}
\hline & \multicolumn{2}{|l|}{$250 \mathrm{kWE}$ Cost Estimate } \\
\hline & \multicolumn{1}{|c|}{ 1000/yr quantity } \\
\hline Turbine Generator & $\$ 26,500.00$ \\
\hline Feed Pump & $\$ 4,300.00$ \\
\hline Hot Well & $\$ 1,200.00$ \\
\hline $\begin{array}{l}\text { Power } \\
\text { Conditioning/Control }\end{array}$ & $\$ 22,000.00$ \\
\hline Heat Exchangers & $\$ 43,000.00$ \\
\hline $\begin{array}{l}\text { Piping and } \\
\text { Instrumentation }\end{array}$ & $\$ 13,000.00$ \\
\hline & $\$ 110,000.00$ \\
\hline Total & $\$ 440.00$
\end{tabular}

Table 5: $250 \mathrm{kWe}$ System Cost

The cost estimate does not include profit, bond, site preparation, or installation costs.

\section{Power Conversion and Plant Control-}

A large part of the system design involves converting the high-speed generator output to a 50/60 Hz sinusoidal output for the grid. Variable heat source input to the system affects the temperature and mass flow into the turbine. Variable speed turbine functionality allows the highest efficiency output over a wide speed range. As the speed drops; the voltage from the generator drops. This complicates the plant control and changes the converters needed for proper operation. A lower cost alternative is to operate at a fixed speed, however, the waste heat source may not be suited for this duty.

\section{Converter Description-}

Six different converters are considered for this evaluation. These six designs come from the consideration of two types of generator input bridges and evaluating each type at three different power levels. The two types of input bridges will be designated as "active" and "passive". All designs use an IGBT output bridge to interface with the utility grid.

The term "passive" will be used to denote an input bridge which makes use of a single type of semiconductor, high speed diodes. In this type of bridge the diodes will conduct current only during the small time window when the phase-to-phase generator voltage 
exceeds the voltage present on the DC bus. The intervals during which energy is transferred are determined solely by the instantaneous conditions of the DC bus and the output voltage. Hence, the name "passive", because the bridge is a passive participant in a process controlled by other circuit elements.

The term "active" will be used to denote an input bridge which makes use of two different types of semiconductors, high speed diodes and Insulated Gate Bipolar Transistors (IGBTs). An active rectifier, when properly controlled, can be used to extract a tailored current waveform from the generator during intervals when the generator voltage does not exceed the DC bus voltage. This ability to extract current, and thus power, allows the system to operate across a very wide speed range and to produce very highly optimized waveforms.

Other than the differences detailed above, input rectifier type and power level, all of the designs were the same with regard to system topology and theory of operation. Incoming AC power is converted into power flow across a DC bus. The DC bus is in turn used to provide power to the output inverter which interacts with the utility grid. This interaction will produce properly phased sinusoidal currents in the utility legs and deliver recovered energy into the grid. So long as an energy balance is maintained between input and output, this type of system can be used to deliver power from one AC source into another. Its principle advantage is that the two AC systems can be operating with different voltage, frequency, and/or waveforms.

A distinction in the $50 \mathrm{~kW}$ converters is that they are designed for operation with a 208 Vac utility connection. The remaining four systems, operating at 100 and $250 \mathrm{~kW}$, were designed for operation with a $480 \mathrm{Vac}$ utility connection.

This decision was made because most small physical plants are designed around a 208 connection. Since this voltage range is intended for smaller demand plants, utility providers typically limit the ampacity of these connections to 200-300 amps. The operating currents for a $50 \mathrm{~kW}, 208 \mathrm{Vac}$ systems are approximately 140 amps and the current for a $100 \mathrm{~kW}, 208 \mathrm{Vac}$ systems are about 280 amps. It was felt that interaction with a 208 grid at currents above 200 amps would be problematic and therefore the 100 $\mathrm{kW}$ system was designed for 480 Vac operation.

\section{Power Flow-}

Looking at the schematics for the active and passive input rectifier configurations, it is quickly seen that the two system designs are very nearly the same. (Figures 8 and 9) In fact, the only significant differences are that the input rectifiers themselves are different and the complexities of the required controllers are quite different. Therefore, the two schematics shall be considered equivalent for the following power flow discussion. Differences will be noted as required

Power enters the page at the top right corner via the three phase terminal labeled "Gen In". Power flow continues to the left through the over current protection fuses F1, F2, and $\mathrm{F} 3$ up to contactor $\mathrm{K} 1$. For normal operation $\mathrm{K} 1$ will be closed and dump resistor contactor $\mathrm{K} 2$ will be open. If a fault occurs during normal operation then $\mathrm{K} 2$ will be closed to provide a guaranteed electrical load for the turbine/generator. 
Continuing to the left, the three phase rectifier (either active or passive) will provide power into the DC bus. Power flow out of the DC bus is controlled by the second three phase bridge, the output inverter. This IGBT bridge will be used to form a pulse width modulated (PWM) reconstruction of a utility sin wave. The high frequency signature of the PWM process is removed by the combined actions of $\mathrm{L} 1, \mathrm{C} 2, \mathrm{C} 3$, and $\mathrm{C} 4$ which together form a three phase output filter with a corner frequency of approximately 550 Hz.

Normal power flow will continue through the output fuses F4, F5, and F6 and the output contactor K3 finally reaching the output transformer X1 and circuit breaker CB1. The output circuit breaker provides the final stage of over current protection.

The output transformer performs several important functions in the overall system design. Due to the construction techniques used in standard utility transformers, this device will not pass high frequency signals and thus is used as the final stage of output filtering. Additionally, X1 provides a bridge between the floating reference output of the IGBT bridge and the ground referenced utility grid.

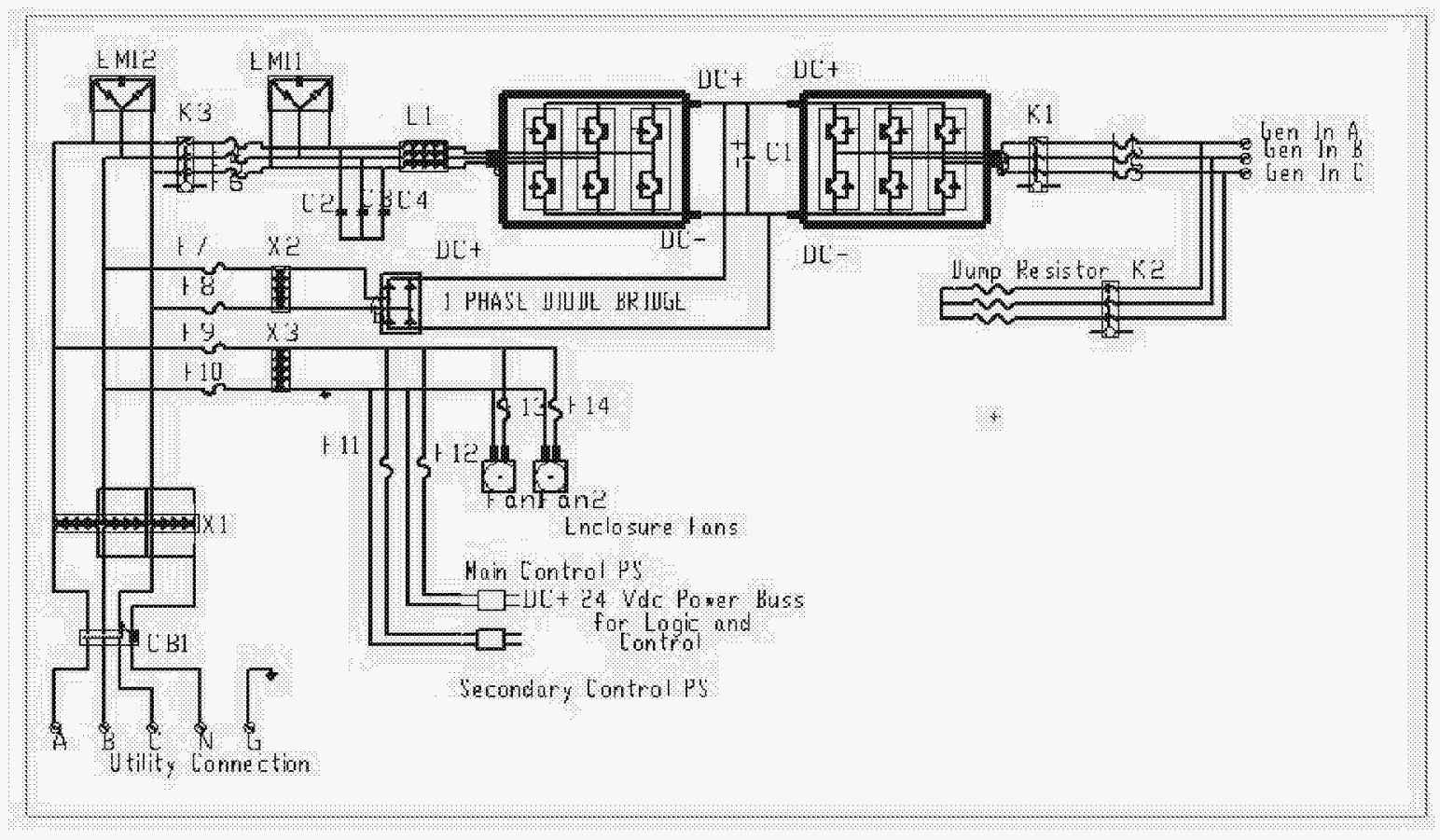

Figure 8-Active Converter Schematic 


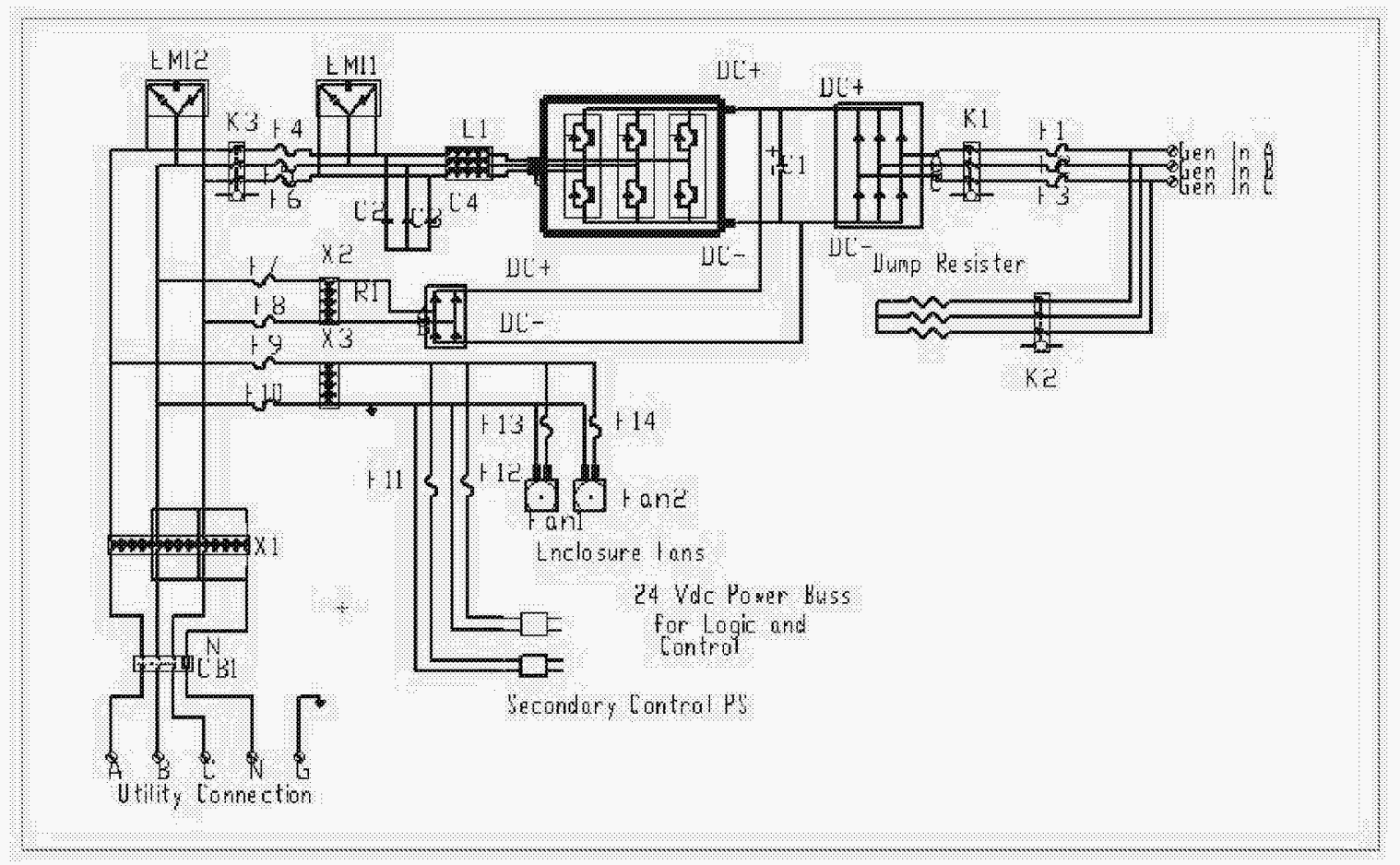

Figure 9- Passive Converter Schematic

\section{STARTUP}

Once installed at a customer location, system startup will begin with the manual operation of the output circuit breaker CB1. This will energize the output transformer X1 which in turn will provide power to the pair of control transformers X2 and X3. X2's only role in system operation is during startup.

After power is applied, $\mathrm{X} 2$ will deliver power to a small, single phase rectifier bridge which will pre-charge the DC bus to approximately $85 \%$ of its normal operating voltage. Pre-charging of the DC bus is required to prevent hi inrush currents causing damage when $\mathrm{K} 3$ and/or $\mathrm{K} 1$ are eventually closed.

Transformer X3 will now provide power to all system fans and control power supplies. After a short time the control system will boot and system startup will continue under automatic control. When the system controller first starts; all monitored input variables will be checked to verify that the instrumentation is working and that the signals are in range. If all signals are correct, and the $\mathrm{DC}$ bus has finished charging, then $\mathrm{K} 3$ will close and finally, K1 will close. At this time, the turbine/generator set will be initialized to complete system startup. 


\section{REGULATORY REQUIRMENTS-}

Under the terms of this contract, all system designs must comply with UL1741 and IEEE1547. In this section we will discuss how compliance with these two standards will effect/direct the design and testing of the final system. Fortunately, compliance with these standards does not adversely affect either the final design or the process of system design. Rather, these standards dictate that the resulting system must function well, without presenting the end user with any unreasonable risks or causing any noticeable disturbances on the utility grid.

UL1741, like most UL standards, is mainly concerned with the safety of the final system. Most of the UL requirements contained in this standard can be divided into two categories. First, those requirements related to providing adequate electrical isolation and mechanical protection between the user and the hazardous voltages present inside of the cabinet. Second, those related to specific system tests intended to demonstrate that the system does not produce any hazardous results when subjected to abnormal conditions.

The first group, those related to voltage isolation and protection, will be addressed very early in the design process. It will be necessary to provide galvanic isolation between all measured and/or controlled system voltages and the controller itself. The necessary degree of isolation can be obtained thru a combination of opto-couplers and small-signal transformers. Fortunately, the components required to complete these designs are readily available from several IC manufactures. This is do to the wide spread use of high voltage inverters which require UL marks in today's marketplace.

The voltage isolation requirements also directly affect the design of the system power supplies. These requirements will be satisfied thru the use of an off-the-shelf power supply. The supply chosen will have already gained UL recognition and will be integrated into the final system without modification.

The requirements to provide protection for the user from the high voltage inside of the case will be addressed in two ways. First, the cabinet will be designed such that is it impossible to extend a finger or hand held rod into the system and touch any high voltage bus or component. Insulated barriers will be placed adjacent to cooling and fan holes as required to assure that this condition is met. Second, the cabinet will have a door interlock switch which will detect if the user has opened the door. If actuated, this switch will force the controller into a rapid shutdown state which will discharge the hazardous voltages as quickly as is possible.

The second group, those related to abnormal conditions, will be addressed mainly by the proper design of the system topology and by proper component selection. The abnormal tests, as they are frequently called, are intended to simulate the effects of component failures on the final system. In order to accomplish this goal, a UL test engineer will select an arbitrary number of components which will be forced into either an open or short-circuit state. The manor and timing of the simulated failure will also be selected by the UL engineer.

Some fault conditions are so likely to occur during the life-cycle of a product that they are included in all UL test programs. These include input/output open/short, IGBT open/short, diode open/short, contactor open/short. The system will be protected against 
all of these conditions via the number and type of fuses which have been selected and by controller sensing with shutdowns.

Every effort will be made during the design phase to provide for a fail-safe shutdown during all failures. Many abnormal conditions can be detected by the controller firmware which will trigger a fault shutdown. It is however, quite common for UL to uncover a problem in even the best designed systems. We have anticipated this by providing the budget and schedule with an interval to fix, retro-fit, and retest if required following the initial UL testing.

Unlike the UL standard, IEEE1547 does not address any safety issues but is only concerned with the operational performance of the system. This standard defines requirements for the quality of the output waveform, the impact of the system on the utility grid, and the behavior of the controller at specific times. IEEE1547 further defines the manner in which testing shall be performed to verify a systems compliance.

The requirements of IEEE1547 are easily summarized:

1) The system output will not be energized unless the utility grid is energized.

2) When operating, the system will produce only small levels of voltage or current distortion.

3) The system output will not attempt to provide voltage or frequency regulation but will follow the grid at all times.

4) The system output will be de-energized if the utility voltage or frequency is not in a specified window.

5) The system output will be de-energized if the utility grid is suddenly lost.

All of the requirements are easily met. \#1 is satisfied by the system topology which has been chosen. Utility power must be present to energize the control power bus. Thus, it is impossible to start the system if the utility grid is not present.

Condition \#2 is satisfied by the combination of the primary LC output filter, EMI suppression caps, and the output isolation transformer. These components provide high quality filtering of distortion and DC components. The performance of these components will be verified via simulation prior to committing to a final design and again during testing. The remaining conditions, \#3-5, all relate to the behavior of the control system during normal and abnormal conditions. These behaviors will be part of the original design specification and will also be verified via simulation and during testing.

\section{Summary-}

It is difficult to design a production ORC system that can obtain good efficiency over a market that has a wide range of waste heat flows and temperatures. Every waste heat source has variables that affect the heat exchanger and turbine design. The gas or liquid properties of the waste heat, the flow rate and temperature greatly affect the heat exchanger design. Small changes in the waste heat stream have large consequences for the heat exchanger and turbine design. While the system may run in this off-design 
condition, the power output will be lower. This will yield a higher $\$ / \mathrm{kW}$, which reduces the ability to sell into the market. Therefore, it is important to find a suitable waste heat source that can support the higher cost of the ORC system.

\section{References:}

1. Cole R.L., Demirgian J.C, and Allen, J. W., "Predicting Toluene Degradation In Organic Rankine-Cycle Engines", Argonne National Laboratory, Argonne, Illionois under USDE contract W-31-109-Eng-38.

2. Jain, M.L., Demirgian, and Cole, R.L., "Organic RankineCycle Power Systems Working Fluid Study: Topical Report No.1 - Fluorinol 85. ANL/CNSV-TM-182, September 1986

3. Zyhowski, Gary J.,"HFC-245fa in Organic Rankine Cycle Applications", Honeywell Literature (no date) 